\title{
TO IDENTIFY A B2C OPPORTUNITIES FOR COMPASS GROUP WHICH IS B2B COMPANY
}

\author{
Mannat Kaur \\ Amity International Business School, Noida \\ DOI: 10.46609/IJSSER.2021.v06i06.015 URL: https://doi.org/10.46609/IJSSER.2021.v06i06.015
}

\begin{abstract}
B2B marketing differs substantially from the marketing of consumer goods or services since the purchasers themselves don't utilize the items or services. In contrast to consumer markets, where the people who purchase products and services directly consume, the essence of business markets is the consumption of particular companies. This work is based on this key idea that has major consequences for organizational purchasers' satisfaction for marketing strategies and associated programs. The buying methods used to buy products and services is another key component of B2B's marketing. Decisions are taken relatively rapidly in consumer markets, the amount of risk is modest, at least for common products, and the focus is mostly on the emotional components of a purchase. Potential risks are typically fairly significant in B2B marketplaces; thus, choices take far longer and involve far more individuals. The type and manner of connection between organizations therefore relies on an awareness of the demands of individual consumers and the willingness to offer and exchange information.
\end{abstract}

Keywords: B2B, Business, compass group, responsible biryani, marketing

\section{COMPASS GROUP}

\section{About}

FTSE 20, a worldwide revenue corporation London - Based, is the Compass Group. The company is the global leader in contract food and support services in 45 countries. In the 'Fortune 2016 Change the World' list of 50 firms, Compass is also the world's ninth largest employer. Of the 100 Fortune corporations, over 96 are customers. Compass' international reach, product expertise and industry understanding allows users, schools and colleges, hospitals and remote areas to gain a complete experience, amongst other things. As a 100 per cent subsidiary of the Compass group PLC Group, Compass Group India has maintained world class standards of performance across India and served Indian corporate demands, health care and education sector since 2008. It encompasses some of India's most renowned developments, serves over 40million 
meals a year and manages over 170 million square feet of high-end structures. Compass Group India operates across India at more than 450 customer sites. It's about making jobs come alive every day! Every day.

Compass Group is an employer of equal opportunities. At Compass, we vow to treat all applicants and associates equitably on the basis of their talents, achievements and experience, regardless of race, national background, sex, age, handicap, veteran status, sexual focus, gender identity or any other legally protected classification.

Our Vision - sets out what we want to be. To be a world-class provider of contract foodservice and support services (inc facilities management), renowned for our great people, our great service, and our great results.

Our Values - these set out what we collectively believe in and guide our behaviors Can-do Safely, Responsibility, Win Through Teamwork, Passion for Quality, Openness, Trust and Integrity

Our Mission - sets out how we are going to achieve this Everyone in Compass is committed to consistently delivering superior service in the most efficient way, for the shared benefit of our customers, shareholders and employees.

\section{OVERVIEW}

\section{Social media marketing:}

1. They have a decent amount of following on Instagram which around 13k-14k, that would be okay for a restaurant's social media following

2. They promote a lot of humble acts on social media.

3. They do promote and post many inspiring quotes, with their chefs and the staff working over there. Also their positive thoughts are being shared. Which is a very good marketing tac tic as now days people prefer to engage with positive perspectives and things. Especially when a brand portrays it way too much. It tends to influence people and the consumers out there.

4. The staff seems to be extremely polite and understanding the needs of the customer. As we all know that's how a brand or a company is most likely to have a positive and good point of view or feedback towards the company when the staff is polite, as it makes a huge difference.

\section{On Facebook:}




\section{International Journal of Social Science and Economic Research}

ISSN: $2455-8834$

Volume:06, Issue:06 "June 2021"

1. On Facebook they look more than a food and beverage catering company. As there are plenty of brand endorsement of their clothing merch.

2. The price of their merch or the products of their clothing brand is around 150 to 200 dollars. Which actually is a lot for many people, especially to pay for a brand that's based on food or catering company.

3. There is a lot of focus on the development towards the society they have made. As in all their humanitarian acts like helping people all around their area and promoting little acts of kindness.

4. The followers don't match with the engagement that is seen on their posts and timelines.

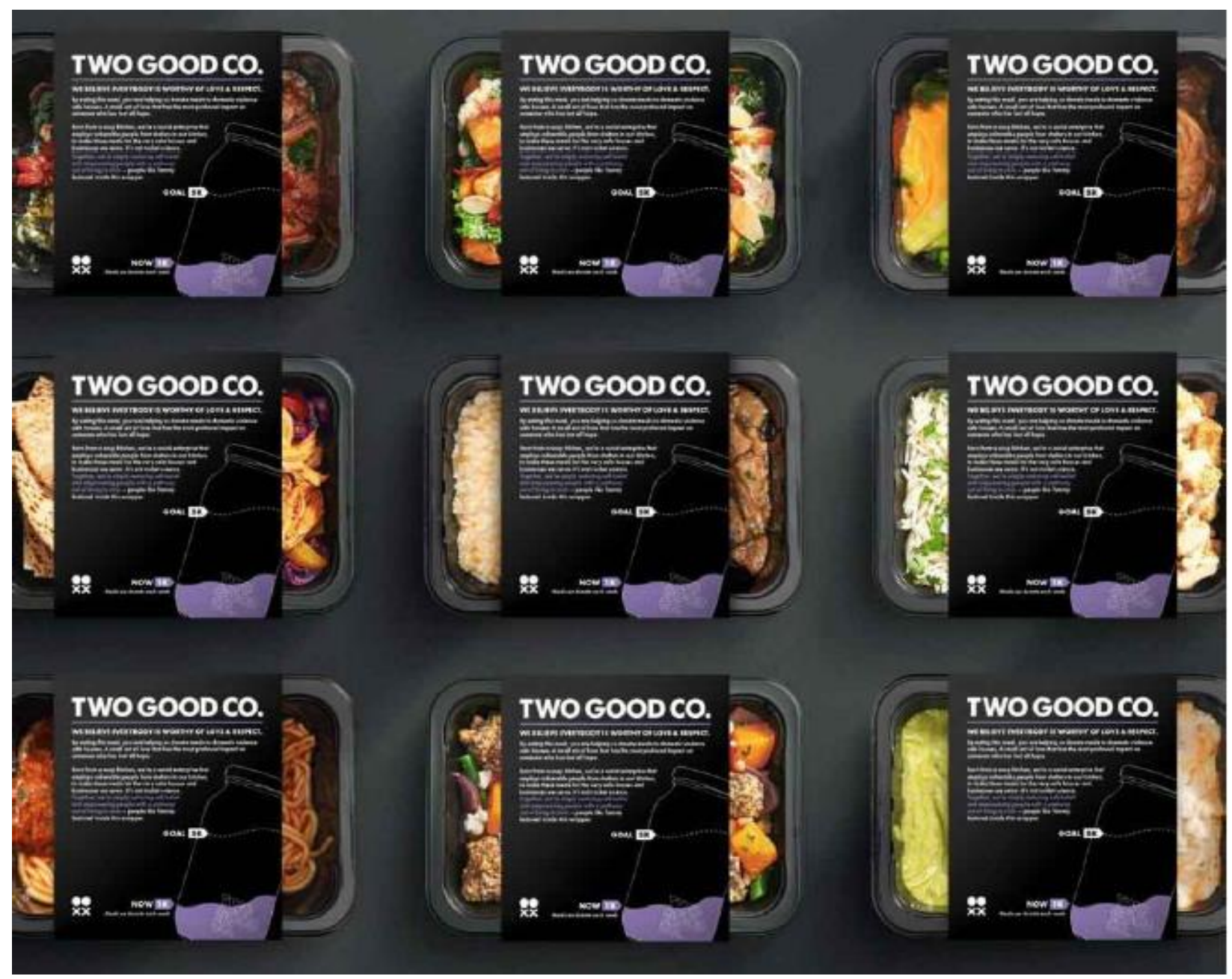

Figure-1: Too good co, products 
International Journal of Social Science and Economic Research

ISSN: 2455-8834

Volume:06, Issue:06 "June 2021"

\section{Q1. What all things do they offer when it comes to food?}

A1. Two good co, seems to have a lot of options when it comes to their menus.

Various options like Vegan, vegetarian, gluten free, dairy free, nut free, refined sugar free andegg free. Etc. Which also happens to be health friendly to the consumers out there dealing with any health issues or so.

\section{Q2. How does the food quality seem?}

A2. The quality of the food seems to be very good as that's what social media and their website shows. But yes the packaging is done in a standard way. Which makes the food look attractive.

\section{Q3. How are the prices?}

A3. The prices of the foods seem pretty reasonable especially, when we take a look at thequality and packaging of the food.

\section{Q4. How is the staff?}

A4. The staff happens to be extremely friendly and cooperative towards the customers aroundthe. They all also have a very helpful nature.

2. B2B Marketing: As the name implies, the marketing of products or services to other companies and organizations is a business-to-business concept. It has a number of important contrasts from B2C marketing that is consumer-oriented. In general, the content of B2B marketing is more informative and simpler than the material of $\mathrm{B} 2 \mathrm{C}$. Business purchasing choices are more centered on the bottom-line income effects than those of consumers. Return on investment (ROI) is rarely an issue for the daily individual — at least in money — but for business decision makers it is a major emphasis. B2B vendors generally sell to purchasing commissions with several important stakeholders in the current environment. This gives the landscape a complicated and sometimes difficult one, but as data sources stronger and more precise, it improves considerably the capacity to draw up committees and to reach customers through appropriate tailored information. Any company selling to other firms. This may happen in various ways: subscriptions for SaaS (Software-as-a-Service), security solutions, tools, accessories, offices, you name it. Many companies both come under the framework of B2B and B2C.

\section{RESPONSIBLE BIRYANI}




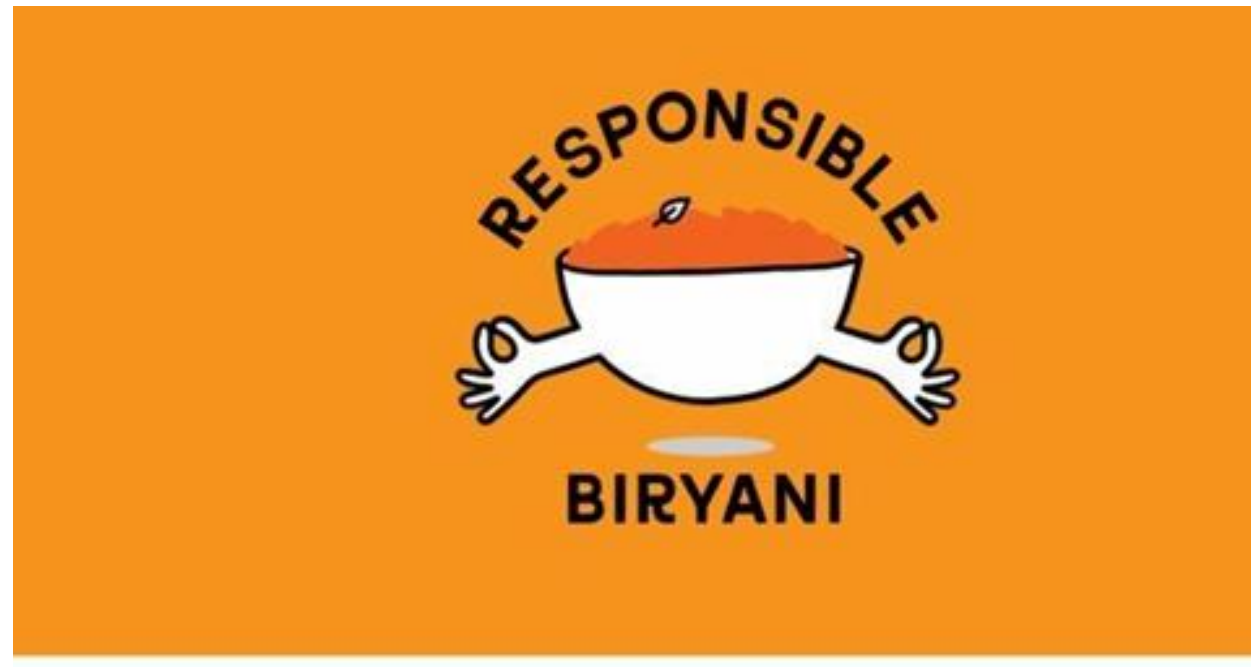

\section{With Great Taste Comes Great Responsibility}

\section{COMPANY PROFILE}

\subsection{About:}

India's love of biryani is no casual business from splitting the Internet and uniting neighbors. They got it, and hey! Whether it's been a hearty supper at home or a delicious working group lunch, biryani always has our back. Biryani has been a sort of cuisine for too long, reserved for special occasions. While our favorite biryani in the culinary revival continues to thin out and fancy the pizzas and parathas of the globe.

They help biryani shake loss at Responsible Biryani and have fun! It's like biryani, but lighter, healthier and culpable! The heart of Biryani from Responsible Biryani are responsible grains such as super grain quinoa, millet, etc. The next level of responsibility lies in the correct balance between spices and healthy fats such as Olive Oil and Ghee. With perfect authenticity and a perfect initial approach, the natural sweetness is reached altogether.

VISION: Consider a society in which young people are working leaders and strive to open doors for women's jobs. Nutritional, properly prepared meals - exclusively with quality ingredients, which are intended at a fair price. Enter the respect and decency that are deserved of all visitors and workers. We shall be guaranteed fair gain by sustaining these objectives, which will enable us to contribute to the community we serve. 
International Journal of Social Science and Economic Research

ISSN: 2455-8834

Volume:06, Issue:06 "June 2021"

\subsection{Added Value:}

- Offering distinctive meals, good services and stylish surroundings.

- Improve your health, extend your life and cure diseases.

- Make people know more about catering for the biryani that can lead to this sector's growth.

- Promoting the local economy and Biryani traditional culture based on certain government programmes.

- Lower the demand on local work.

\subsection{Keys to success:}

- Continue to create new clients.

- To maintain customer relationship management.

- By advertising, things and brands are being commercialized.

- Build the marketing channel of the first class.

- First-class employees and trainers.

- Set up the first-class business and learning organization.

- Set up long-term supplier partnerships.

- Use growth strategy at the mature stage and nationwide establish restaurants.

\subsection{Objectives:}

- Customer Satisfaction and Loyalty

- Generating Restaurant Traffic

- Achieving Specific Financial Goals

- Building the Restaurant Brand

\subsection{Locations:}


- Bangalore (Karnataka)

- Gurugram (Haryana)

\subsection{Management:}

- Archive: That's the fundamental point. It has a personal profile, time to quit, why you left, where you went and what you are doing today. It is also vital to record their methods of contact and enable the management speak regularly with them so that they may be used when they are expanding the restaurant in the future. This can contribute to reducing the HR costs and might be considered an HR reserve.

- Performance: For staff who are responsible for ordering food. Based on their selling performance, Responsible Biryani will reward them and can receive commissions on various products.

- Management software: At the mature stage, the restaurant will develop a software which is used to manage employees.

\subsection{Kitchen cost control:}

Kitchen is the heart of the company and decides whether or not to succeed the restaurant. Founding the business stage and creating branding is of great importance. It takes long-term investment and hence requires precise management regulations and management teams. The company must achieve a uniform standard, size and procedure in order to enhance efficiency, reduce the costs to ensure food quality, quality and speed of service.

\subsection{Internal and external relationship:}

- To look for and work with other outlets with comparable services and to study talent, we may also buy local items of flora if possible.

- Maintain a strong investment partnership.

- Continue to increase social reputation, get assistance and support in the media, community and the public.

\section{RISK MANAGEMENT}

1. Market Development Risk: People may at present not know what the products of flora are and may not attempt, this is a major concern. To lead the concept of consumption, we must employ marketing, public relations and advertising. 
2. Competitor's Risk: There will be many rivals or imitators in the process, since this is a brilliantly perspective new industry. It is therefore vital to maintain the fundamental skills, to continue producing innovations, to maintain old clients, to establish a reputation and an influential brand and to enhance its image.

3. Operational Risk: There might be various dangers throughout the operation, such as issues with supply, lack of planned effects on public activities, shortage of cash, etc. Therefore, appropriate preparation is needed to prevent these risks: educating staff, setting up a learning organization, guaranteeing finances. In order to make the workers feel pride of belonging and freedom, we can lower the risks of communicating with the customers and partners, enhance the HR management and the construction of corporate culture.

4. Financial Risk: It is very vital to create credentials and reputation in the very start of running business, since money is limited, to try to collect funding from various sources.

5. Skill Risk: During operation, the outflow of the staff may disclose certain essential talents. In order to overcome that problem, we will get proprietary skills and assign secret clauses to staff in order to limit the chance of leaving staff.

\section{TYPES OF PRODUCTS:}

\section{Hyderabadi \& Dum Biryani}

- Hyderabadi vegetable biryani

- Bangalore dum chicken biryani

- Hyderabadi chicken biryani

- Bangalore mutton dum biryani

- Hyderabadi mutton Biryani

\section{Millet \& Keto Biryani}

- Millet vegetable biryani

- Millet chicken biryani

- Keto chicken biryani

\section{Fusion Biryani (with a Mexican Twist)}


- Chipotle paneer dum biryani

- Chipotle chicken biryani

\section{Kebabs}

- Lehsuni chicken tikka

- Chicken malai seekh

- Achari paneer tikka

- Hara bhara kabab

\section{Dessert}

- Gulab jamun

- Gud daliye ki phirni

\section{Sides}

- Salan

- Jeera raita

\section{MARKETING ANALYSIS SUMMARY}

\subsection{SWOT Analysis}

\section{Strengths}

- Clean and tidy: Clean and neat are the quality of any huge restaurant that you'd experience. If your facility is clean and clean, many people would be attracted. Hotelsand restaurants are usually incredibly dirty, stinking and flying all about. In a neat and clean environment with a pleasant environment your food chain will thrive and will bring customers,

- Cheap prices: The folks in the Upper Middle have usually large five-star hotels and restaurants that are quite expensive. If you give the same service at a lower cost, thenyour food chain will draw the top and middle classes.

- Better service: Delivery outlet is always a game of service and Responsible biryani 
International Journal of Social Science and Economic Research

ISSN: 2455-8834

Volume:06, Issue:06 "June 2021"

makes sure that deliveries are done in the best possible way. Including packaging andnoncontact delivery mode in the pandemic.

- Variety of products: One of the things that people don't like about an outlet is the small menu. If your menu has several things and plates, it will provide the consumers a nice impression. They would like the outlet to have well-equipped people who are able to cook a range of Biryanis.

- Brand Image: The new brand in the region that people flock to see will be your outlet. There are other hotels and restaurants, but people have been previously. The new brand has its own appeal, investors, and many people are drawn to it. If you produce a good impression successfully, it will make them order again.

\section{Weaknesses}

- New establishment: That said, many people love the new eatery previously. However, many people remain loyal to the old brand in the demographic. The notion of a new brand or restaurant will not readily convince you. More than a new name, they want. You have to give them something fresh and distinct if you want to wow them. You will not come if you provide the same services with a different name.

- Limited funds: When it comes to delivering clients a unique experience of visiting their site, a lot of investment would be needed in various service sectors. Like nice position, well-trained lawns, lovely gardens and well-trained people on the hotel premises. It would cost a lot of funds and resources to provide such services to your consumers. You would lose a large portion of market share if you did not offer such distinctive services.

- Lack of Uniqueness: An outlet's unique experience is such a quality that customers would always come it. At the moment, this unique experience component is lacking at your restaurant as you have less resources. Without this functionality, only your rivals, but not new consumers, would attract unhappy consumers.

\section{Opportunities}

- Pandemic creating a lot of delivery needs: A noticeable outcome of the pandemic of COVID-19 is that previously busy food places are vacant while employees and management are adapting to new business realities. As we remain home to shut down the effects of the virus on our first respondents and vital personnel, many of us have turned to food and food services for the first time. In order to help everyone, support a beloved local restaurant, avoid going off and just enjoy comfort during these difficult times, the 
hospitality sector has adapted. Many of us have understandable questions regarding food safety. Some safety measures should be taken into account while ordering or taking delivery of meals.

- Delivery etiquette: Given the nature of the dissemination of COVID-19, interaction with others might lead to the greatest risk of infection. Responsible biryani in the food service industry now allows consumers to pay for cash transfer or credit card handling by telephone or online, both of which might possibly bear the virus. Recall that the front porch or doorstep is now the workplace of the delivery person when ordering delivery. Use the contactless delivery option if available to leave food for both of you at your door and to make it safer. If contactless delivery cannot be achieved and an order must be accepted directly, take the same procedures as with the drive window.

- Healthy alternatives: Biryanis are often considered unhealthy, well Responsible biryani brings you many options in the health corner including less fat as well as keto friendly biryanis. 


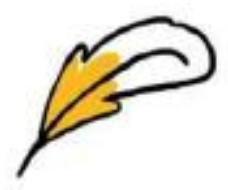

\section{LIGHT}

\& HEALTHY

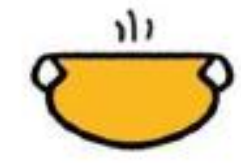

TRADITIONAL COOKING STYLE

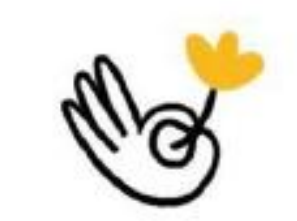

\section{AUTHENTIC}

\section{FLAVOURS}

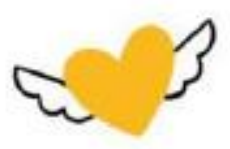

\section{LESS FAT}

Figure-2: Specialty of responsible biryani

\section{Threats:}

- Big brands in the area: Old and renowned brands of restaurants operate in the region. So costs with the existing revenue are very tough to satisfy. Naturally, one day, this will be a good business. However, in the present conditions it will be very difficult to reach that point. 
International Journal of Social Science and Economic Research

ISSN: 2455-8834

Volume:06, Issue:06 "June 2021"

- Reduced prices by competitors: The outlet is not able to meet the revenues at different operating costs, such as salary for its employees, building rent, supplier cost and building maintenance charges. It is simpler to establish a good restaurant, but it is harder to retain the same position for some time. This is because in your balance sheet, you have to bear many fixed and variable costs, especially if businesses are not making enough revenue.

\subsection{PRODUCT POSITIONING}

Responsible biryani will be able to establish ourselves as an excellent restaurant with a healthy, pleasant and profound cultural atmosphere. They will also give unparalleled flavor and service. We target rich, high income clients and affordable, tasteful businessmen. Therefore, they placed the pricing on a moderate level, with a mature, exquisite, service and taste.

\section{- Quality positioning}

The position of excellence is three essential points: sophisticated and delicious Biryani, stylish pleasant service. Three tastes should be added: 1. The chefs' taste, Constant innovative taste suited to all clients and Flavor that continues to evolve quickly according to the necessity for company expansion. It should always continue to learn from other companies and make new recipes. We will design our own features based on the new things we discover. We also provide our waitress professional service training to ensure quality of service.

Function of health: health, culture, entertainment and home comfort. Not only the taste but also the health of clients should be focused. Customers can make wonderful meals, give them a lovely look and a nutritious meal. It should allow the consumers to feel respect, care and affection for their service and being at home, it should also allow them to feel content with what they're paying for.

\section{- Price positioning}

Moderate: To conduct consumers with top-grade products and excellent services with moderate prices.

Psychological Pricing: Psychological pricing is to establish prices based on various customer demands.

Reputation Pricing: All the clients are thinking about pursuing something's reputation. On the basis of this approach, the company may set prices higher than equivalent items for functions. It removes psychological obstacles for consumers and makes them feel confident and secure, as well as satisfying consumers. 


\section{International Journal of Social Science and Economic Research}

ISSN: $2455-8834$

Volume:06, Issue:06 "June 2021"

\subsection{Marketing strategies}

Marketing is the basis of development for the catering sector. The restaurant will employ brand marketing, advertising and public relations of publicity.

\section{Brand Marketing:}

When developing diverse brands, it will provide customers diverse sensations. Management of a firm with contemporary theories, client requirements, and outstanding service develop a reputation (Specialist Catering, 2008).

1. Individual, Unique, and Visualized services: With the growth of everyday life, demand for consumption aims to be personalized, making businesses highlight the needs of individuals, offering personalized services to clients depend on the place, time, goal and image of the company. It should aim to construct a restaurant with function of enterprise, romance, leisure and function based on our company position and management. A huge number of clients focus not only on the product consumption but also on the reputation of the goods and their image in terms of services (Specialist Catering. 2008).

2. View people's needs such as emotional life and social activities: The emotional lives of the people and consumption levels for all sorts of emotions is one of the distinctive features of the restaurant. One of the most crucial aspects is that the company should do its best. Customer demands, emotional communication, business conferences, parties. People search for a better environment and outstanding services, good venues and a wide range of meals.

3. View customers' needs on knowledge and information: The company is more information-based, individuals start to be more interested in the information. Information for those who manage a good business is becoming increasingly crucial. This restaurant might be the one-stop shop for more people and marketing (Alina Maria Andrie,2009).

\section{Advertising:}

The properties are rapidly expanding and encompass a wide range. Making cultural publicity for companies and social non-profit organizations. The plan is to get recognized culinary experts to introduce scent, color, taste and flavor in particular on the TV show for product advertising.

1. Social media marketing: social media is a key aspect of running a contemporary business and becomes a popular marketing platform that helps you develop your client base and convert visitors for the first time into regulars. If your images of specials and promotions are constantly basic and easy throughout each channel, or whether your 


\section{International Journal of Social Science and Economic Research}

ISSN: 2455-8834

Volume:06, Issue:06 "June 2021"

positions are levelled down and promoted on the best performers of your restaurant marketing plan is a key element of your plan in the social media. One basic rule is to strive to publish at least three times a week on your social media accounts or to risk losing your involvement with your fans. Try posting multiple times a week with the following guidelines to identify inventive restaurants that will certainly match your audience. Whether you run your restaurant online presence, transfer the responsibility to a dedicated staff member, or employ someone as your restaurant's full-time marketing manager, other restaurants that slay social media games and drive digital visitors into business are always beneficial.

Responsible biryani is quite active on Facebook, YouTube and Instagram (see figure 1,2 and 3)

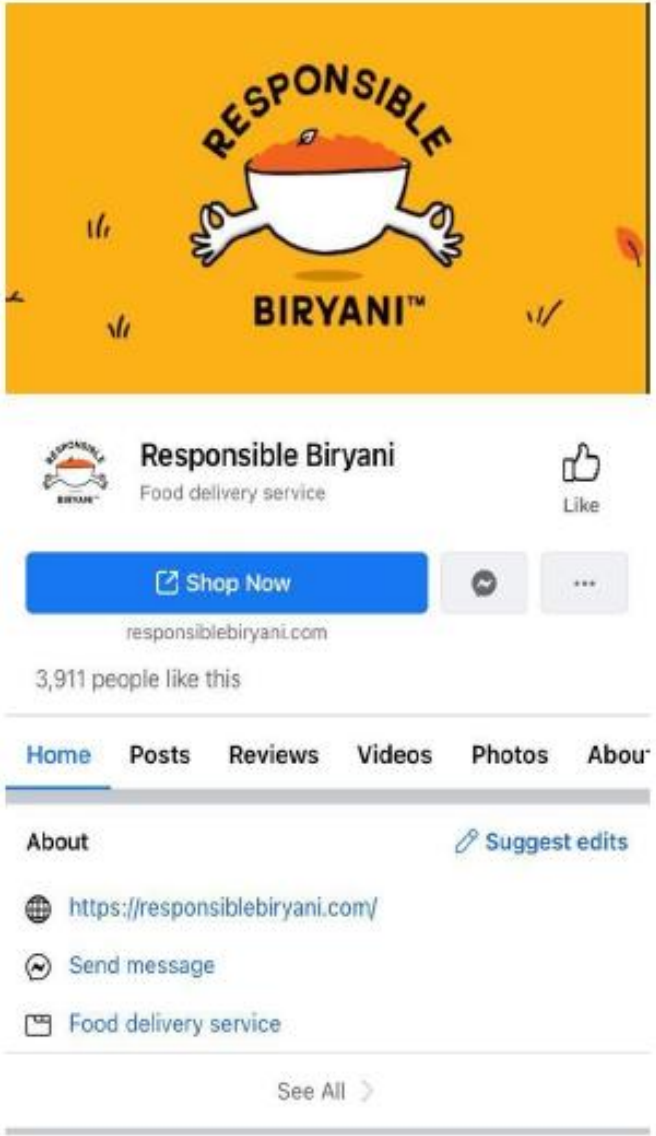

Figure-3: Facebook page of responsible biryani

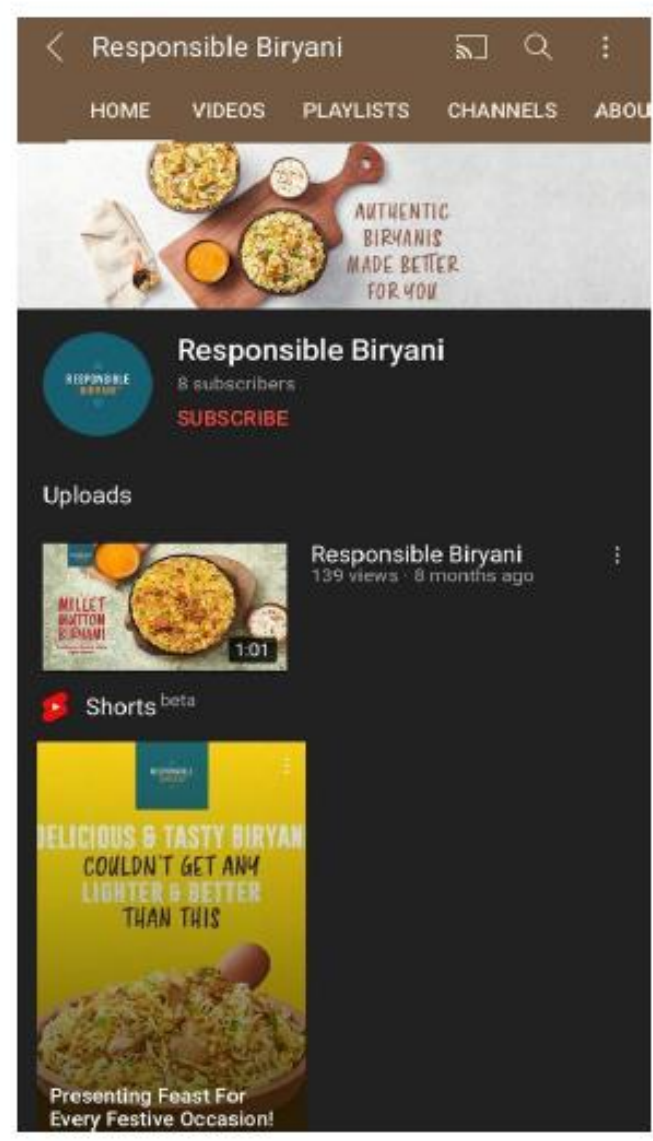

Figure-4: YouTube channel of responsible biryani

Renowned restaurant management is all. An unchecked mis review might imply that many potential consumers ask whether they are going to visit their establishment. Fortunately, $71 \%$ of 
people are more willing to suggest a firm on social media, which replies immediately to them. So, whether a consumer has made a bad or favorable assessment of your social media; make sure that you reply. In certain cases, you may quickly remedy the matter and the negative review can be taken down by the people if you react to a bad review. Checks also let you realise the strengths and shortcomings you should have as a restaurant. See how consumers love to improve when responding and taking the effort to improve. It is by far the most popular type of social media advertising with 93 percent of social media advertisers utilizing Facebook advertisements.

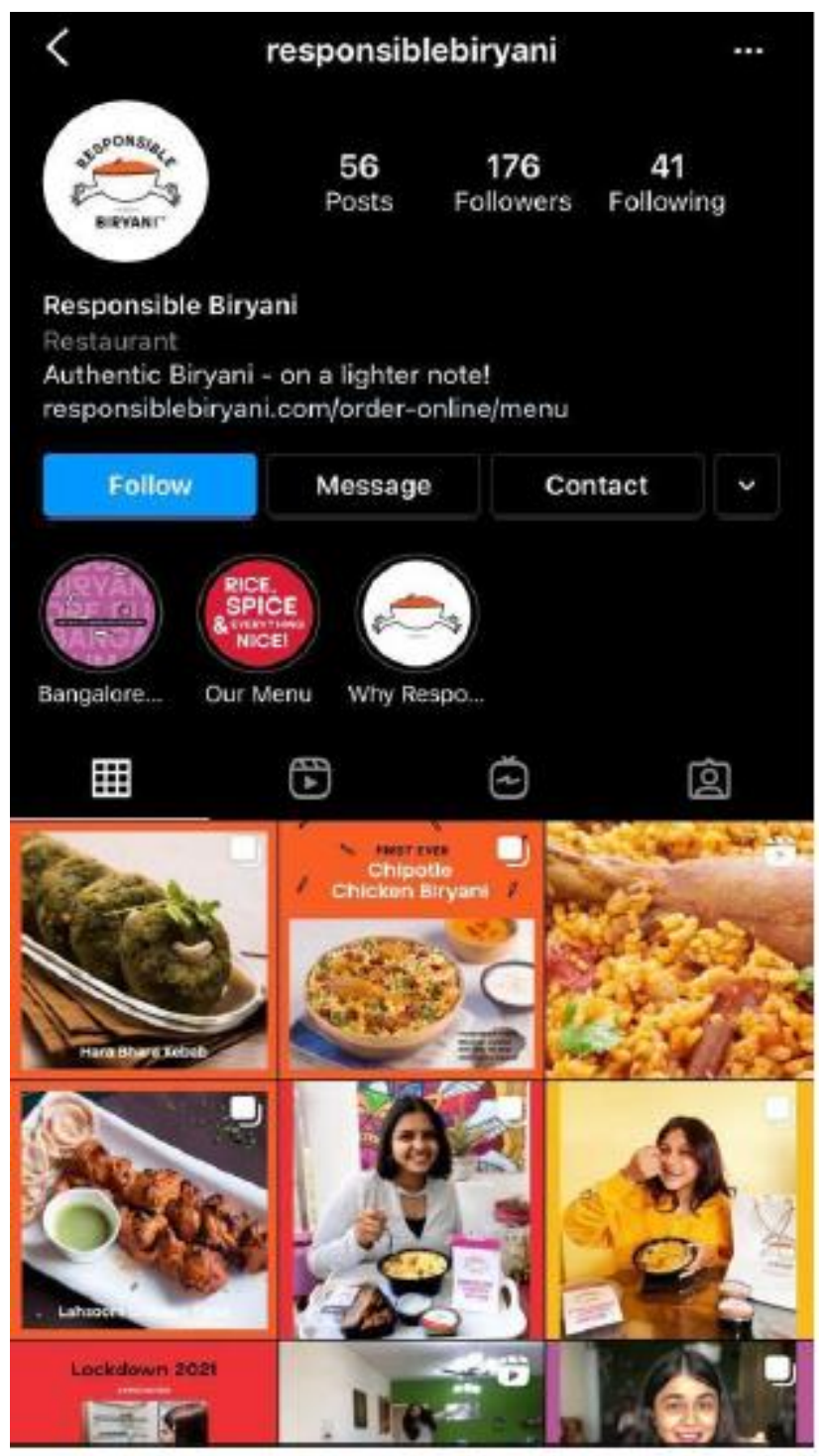

Figure-5: Instagram page of responsible biryani

The reason why Facebook advertisements provide restaurants a godsend is due to the extensive 
targeted alternatives. You can geo-target using Facebook advertisements, which means advertising solely to individuals in your region. This is particularly essential since many restaurants use different advertising media such as television to spend their marketing money ona client base that is not in their local region.

2. Newspapers and Magazines: The newspapers and renowned publications routinely publish the restaurant's picture, the marketing idea and the culture of the organization.

3. Publicizing internally: Publishing at the service with many menu kinds, such as today's menu, children's menus, lovers, weekends, etc. To impress you, it is vital to design a lovely and appealing food.

4. Mail advertising: It will publish a brochure, business communication, postcards and so on for client delivery. It is appropriate to create new items for a particular occasion and to entice shoppers at Festivals.

\section{Relationship marketing:}

1. Awards and customer loyalty: The restaurant establishes the reward rule and creates the company's customer loyalty archive. It will develop guidelines, such as sending the VIP card from Responsible biryani, establishing client records, giving unique service alternatives, and awarding them additional and noble services. Select some of the frequent customers to form or encourage them to be a spokesperson for another client.

2. Customer's financial benefits: We may offer better services for those committed customers at the same pricing. The outlet offers these frequent client's concessional privileges.

3. Customer's social benefits: By enquiring on client requests, the restaurant will offer distinctive and distinct items to create strong customer connections. In order to contact existing and new customers and record their wants and desires, we will assign a dedicated team, knowledgeable with the names and interests of the client, and others.

4. Customers contact: In order to improve the touch with the consumer, the outlet willhave communication equipment and amenities.

\section{REFERENCES}

- $\quad$ www.responsiblebiryani.com

- https://responsiblebiryani.com/order-online/menu 
- Cameron Leone and Miller Peter 2008 Enhancing HRM practice in SMEs using the concept of relationship marketing. USA.

- Chell Elizabeth 2001 Entrepreneurship Globalization, Innovation and Development. First Edition. United Kingdom.

- Jobber David 1998 Principles on Practices of Marketing, second Edition, UnitedKingdom

- Finch Brian 2006 How to write a Business Plan. Third edition. United Kingdom Kotler

- Philip and Armstrong Gary 2010 Principle of Marketing, United state of American Mintzberg H. 1973 The nature of managerial New York. USA.

- Kumar V. Aaker David A. and Day George S. 2002 Essentials of Marketing Research, second edition. USA.

- Lahtinen Jukka and Isoviita Antti 1994 Customer relationship marketing, Tampere, Finland.

- Masterson Rosalind and Pickton David 2010 Marketing on introduction, second Edition, United Kindom 